\title{
Evidence of, and a proposed explanation for, bimodal transport states in alluvial rivers
}

\author{
Kieran B. J. Dunne and Douglas J. Jerolmack \\ Department of Earth and Environmental Science, University of Pennsylvania, Philadelphia, Pennsylvania, USA \\ Correspondence: Kieran B. J. Dunne (kdunne@sas.upenn.edu)
}

Received: 16 November 2017 - Discussion started: 6 December 2017

Revised: 18 May 2018 - Accepted: 19 June 2018 - Published: 25 July 2018

\begin{abstract}
Gravel-bedded rivers organize their bank-full channel geometry and grain size such that shear stress is close to the threshold of motion. Sand-bedded rivers, on the other hand, typically maintain bank-full fluid stresses far in excess of threshold, a condition for which there is no satisfactory understanding. A fundamental question arises: are bed-load (gravel-bedded) and suspension (sand-bedded) rivers two distinct equilibrium states, or do alluvial rivers exhibit a continuum of transport regimes as some have recently suggested? We address this question in two ways: (1) reanalysis of global channel geometry datasets, with consideration of the dependence of critical shear stress upon site-specific characteristics (e.g., slope and grain size); and (2) examination of a longitudinal river profile as it transits from gravel to sand bedded. Data reveal that the transport state of alluvial riverbed sediments is bimodal, showing either near-threshold or suspension conditions, and that these regimes correspond to the respective bimodal peaks of gravel and sand that comprise natural riverbed sediments. Sand readily forms near-threshold channels in the laboratory and some field settings, however, indicating that another factor, such as bank cohesion, must be responsible for maintaining suspension channels. We hypothesize that alluvial rivers adjust their geometry to the threshold-limiting bed and bank material, which for gravel-bedded rivers is gravel but for sand-bedded rivers is mud (if present), and present tentative evidence for this idea.
\end{abstract}

Copyright statement. The U.S. Government is authorized to reproduce and distribute reprints for Government purposes notwithstanding any copyright notation herein.

\section{Introduction}

Almost 100 years ago, Lacey (1930) proposed an empirical relationship relating the width of an alluvial river to its water discharge. Leopold and Maddock (1953) built upon this to derive the hydraulic scaling relations for bank-full channel geometry of alluvial rivers. Decades of research since have added geographic (Parker et al., 2007; Richards, 1987) and morphologic (e.g., braided vs. meandering; Gaurav et al., 2015; Métivier et al., 2016) variety to data compilations and recognized the importance of vegetation and geologic controls that were not originally considered (e.g., Huang and Nanson, 1998; Schwendel et al., 2015; Kleinhans et al., 2015; Nanson and Young, 1981; Ferguson, 1987). Yet the original findings are robust: bank-full width $\left(W_{\mathrm{bf}}\right)$, bank-full depth
$\left(H_{\mathrm{bf}}\right)$, and slope $(S)$ scale as power-law functions of bankfull discharge $\left(Q_{\mathrm{bf}}\right)$ with little variation in the exponents (Parker et al., 2007), suggesting a simple and common organizing principle for alluvial rivers. Cast in dimensionless form following Métivier et al. (2016) and Andrews (1984), with $Q_{*}=Q_{\mathrm{bf}} / \sqrt{\operatorname{Rg} D_{50}^{5}}$ where $D_{50}$ is the riverbed median grain size, $R$ is the particle submerged specific gravity, and $g$ is gravity, the often-called "regime equations" read

$$
\begin{aligned}
& W_{\mathrm{bf}} / D_{50}=\alpha_{W} Q_{*}^{\beta_{W}} \\
& H_{\mathrm{bf}} / D_{50}=\alpha_{H} Q_{*}^{\beta_{H}} \\
& S=\alpha_{S} Q_{*}^{\beta_{S}},
\end{aligned}
$$

where $\alpha$ and $\beta$ are dimensionless parameters. The theoretical underpinning of the regime Eq. (1) is both well known and elusive; it is the equilibrium channel geometry problem (Leopold and Maddock, 1953). Considering fluid mass conservation in a rectangular channel, 
$Q_{\mathrm{bf}}=u_{\mathrm{bf}} H_{\mathrm{bf}} W_{\mathrm{bf}}$,

and friction via a Chézy-type relation,

$u_{\mathrm{bf}}=\sqrt{g H_{\mathrm{bf}} S} / C_{\mathrm{f}}$,

where $u_{\mathrm{bf}}$ and $C_{\mathrm{f}}$ are average bank-full flow velocity and friction factor, respectively, we obtain two relations among the governing hydraulic variables. If $Q_{\mathrm{bf}}, D_{50}$, and $C_{\mathrm{f}}$ are specified (as is typical), one still requires an additional relation among the parameters to close the set of equations and derive Eq. (1) (Métivier et al., 2017).

"Regime theory" is the application of these agreed upon relationships with one additional threshold-channel-based assumption to allow for closure. There are three dominant branches of regime theory, each with their own form of a threshold channel closure assumption that separates regime theory into three distinct schools of thought: (1) assume that river are canals, and thus threshold channels; (2) assume that the transport regime is purely bed load and solve the 2-D flow field to balance fluid shear stress and particle weight at the edge of the channel while simultaneously allowing for transport at the center; (3) assume that the river undergoes an optimization process that maximizes friction in order to reduce fluid shear stress, ultimately resulting in a threshold channel.

The first school of thought is based upon work done to calculate the shape of a stable canal for which the bed material is at the threshold of motion (Glover and Florey, 1951). This work has been extended to natural rivers by Henderson (1961) and offers an explanation for observations of alluvial river width relating to water discharge (Henderson, 1961; Andrews, 1984; Métivier et al., 2017). This line of thinking links well with the second branch of regime theory, which as was established by Parker (1978a). Parker (1978a) solved the 2-D stress field to show that, for a pure bed-load river, the channel is at the threshold of motion for the material at the banks and slightly above the threshold of motion in the center, allowing for the river to transport sediment while at the same time maintaining a stable and consistent width. This model is supported by both global compilations of data and case studies of individual rivers that demonstrate that bedload-dominated gravel-bedded rivers are slightly offset from a threshold channel (Phillips and Jerolmack, 2016; Gaurav et al., 2015; Métivier et al., 2016). Several studies have presented evidence that sediment supply and bank vegetation may drive gravel channels further above threshold (Pfeiffer et al., 2017; Millar and Quick, 1998). Values for Shields stress in gravel-bed rivers reported for a wide range of environments, however, rarely exceed 2-3 times critical.

Parallel to this grain-size-dependent channel geometry is the concept of optimization, which assumes that rivers seek a threshold channel condition by maximizing the flow resistance within the channel to minimize the fluid shear stress
(Eaton et al., 2004; Eaton and Church, 2007). The rational regime theory put forward by Eaton attempts to infer the importance of bank strength given deviations from the threshold condition that is posited by optimality theory (Eaton et al., 2004; Eaton and Church, 2007). However, these relationships are predominantly calibrated on coarse-grained rivers for which research has shown that the influence of cohesive mud is a minor control on the erodibility compared to the weight of the gravel (Kothyari and Jain, 2008). What distinguishes our work from this work is that we extend the concept of Parker's threshold channel model into the space occupied by fine-grained rivers by the suggestion that river channel geometries and their subsequent sediment transport state are either controlled by the erodibility of their beds or their banks. This paper shows the transition from rivers that can be explained entirely by Parker's theory (i.e., channel beds and banks composed of uniform material transported entirely in bed load) to channels that cannot. For natural rivers, this transition most frequently occurs at the transition from a gravelbedded to a sand-bedded condition. This transition coincides with the point at which bed material becomes small enough such that the cohesion of channel banks should become important. What we show is that the sediment transport state is bimodal because grain size is bimodal; the coarser gravel mode is more difficult to entrain than any cohesive bank material, while the finer sand mode is easier to entrain than any cohesive bank material (if present).

As nicely summarized in a recent series of papers (Métivier et al., 2016; Gaurav et al., 2015; Métivier et al., 2017), a useful starting point for the equilibrium channel geometry problem is to consider what we call here the "ground state" in which no sediment transport occurs. In this situation, which may be achieved in a laboratory experiment with a constant $Q_{\text {bf }}$ and no sediment feed, the river organizes such that the boundary shear stress everywhere along the channel cross section is at the threshold of motion (Métivier et al. 2017). Accordingly, the local and width-averaged bank-full Shields stress should be at the critical value, $\tau_{* \mathrm{bf}}=\tau_{* \mathrm{c}}$, and may be estimated assuming normal flow as

$\tau_{* \mathrm{bf}}=\frac{H_{\mathrm{bf}} S}{R D_{50}}$,

where $R=1.65$ is the assumed relative submerged grain density. Setting Eq. (4) equal to $\tau_{* \mathrm{c}}$ provides the necessary closure to determine channel geometry, as first illustrated by Lacey (1930), who solved for the shape of a canal. Of course, natural rivers are not canals; they transport sediment, which requires that their formative Shields stress be larger than critical. Compilations of channel geometry and Shields stress, using global datasets, reveal that alluvial rivers naturally break out into two classes: gravel-bed rivers $\left(D_{50}>10 \mathrm{~mm}\right)$ in which $1 \leqslant \tau_{* \mathrm{bf}} / \tau_{* \mathrm{c}} \leqslant 2$ and sand-bed rivers $\left(D_{50}<1 \mathrm{~mm}\right)$ with $\tau_{* b f} / \tau_{* \mathrm{c}} \gg 1$. The scaling exponents (Eq. 1) for both classes are similar and in reasonable agreement with predictions from "Lacey's law"; however, the coefficients are dif- 
ferent from each other and the threshold channel (Métivier et al., 2017, 2016; Gaurav et al., 2015).

Parker (1978a) provided the first generalization of the threshold channel theory to gravel-bed rivers, which transport sediment as bed load. He recognized that stable riverbanks are incompatible with transport; the transverse slope drives a net flux away from the bank, leading to erosion and channel widening. The solution to the so-called "stablechannel paradox" (Parker, 1978b) lies in the lateral (crossstream) gradient in bed stress; flow velocity and depth increase with distance from the bank. An equilibrium channel may therefore be constructed that is marginally above threshold in the center but at threshold on the banks. Parker (1978a) predicted $\tau_{* \mathrm{bf}} / \tau_{* \mathrm{c}} \approx 1.2$ for equilibrium bed-load rivers, in agreement with observations of natural gravel-bed rivers (Paola et al., 1992; Parker et al., 1998; Dade and Friend, 1998; Parker et al., 2007; Phillips and Jerolmack, 2016) and laboratory experiments (Ikeda et al., 1988; Pitlick et al., 2013; Reitz et al., 2014). In terms of the regime Eq. (1), gravel-bed rivers thus follow expectations from the threshold theory but with a slight offset due to their higher bank-full Shields stress (Métivier et al., 2017). Parker (1978b) also realized that sandy (suspension) rivers cannot behave in a similar manner in that boundary stresses even at the channel margins would be above threshold, leading to erosion. In order to counter slope-driven bank erosion, Parker (1978b) and subsequent researchers (Ikeda and Nishimura, 1985; Ikeda et al., 1988; Wilkerson and Parker, 2010) proposed that the lateral diffusion of suspended sediment outward from the channel center could compensate for inward bed-load sediment transport from the banks. While physically reasonable, suspension channel theories have not provided a satisfactory description of sandy river channel geometry. At present there is no accepted model for the equilibrium geometry of river channels far above threshold.

In the absence of a theory, subsequent research has focused on examining trends drawn from compilations of data on channel hydraulic geometry and bank-full discharge. Examination of gravel-sand transitions along downstream river profiles indicates that the mode of bed-material transport may switch abruptly from near threshold (gravel bedded) to suspension (sand bedded) (Miller et al., 2014; Venditti et al., 2015, 2010; Singer, 2010, 2008; Blom et al., 2017), and hydraulic considerations have suggested that susceptibility to suspension increases rapidly as grain size decreases across the gravel to sand range (Lamb and Venditti, 2016). On the other hand, recent compilations of global datasets have been used to suggest that rivers exhibit a continuum of transport states - from near threshold through to full suspension - and that bank-full Shields stress varies smoothly with grain size, slope, and particle Reynolds number (Parker et al., 2007; Wilkerson and Parker, 2010; Li et al., 2015; Trampush et al., 2014)). Importantly, this new presentation of the data suggests that there is no range in phase space in which rivers cluster near the ground state of a constant threshold Shields stress (Fig. 4). Phillips and Jerolmack (2016) found, however, that gravel-bed rivers do indeed cluster close to the threshold of motion - if the dependence of threshold upon site-specific characteristics (e.g., slope or grain size; Lamb et al., 2008; van Rijn, 2016) is explicitly accounted for. Moreover, while previous data compilations found that bankfull Shields stress increases systematically with decreasing grain size (Li et al., 2015; Trampush et al., 2014), one may readily find data that contradict this trend. Channels formed by seepage erosion in sand (Devauchelle et al., 2011; Marra et al., 2015) are observed to transport sand as bed load and, like gravel bed-load rivers, cluster approximately at the threshold of motion. Similarly, sand-bedded rivers in laboratory experiments also form near-threshold channels (Reitz et al., 2014; Métivier et al., 2016; Federici and Paola, 2003).

We are left with three questions that will be considered in this paper. First, how do rivers transition from near-threshold to suspension states? Second, is the near-threshold channel an attractor or merely a limiting state? And third, how do suspension rivers maintain an equilibrium channel geometry? We address these questions by reanalysis of existing data. We revisit the global data compilations of Li et al. (2015) and Trampush et al. (2014) and argue that natural rivers appear to exhibit bimodal transport states corresponding to near threshold (order 1 multiplier of threshold) and far above threshold (order 10-100 multiplier of threshold). We also show that this bimodal behavior is exhibited within a single river profile transiting the gravel to sand transition. These results lend credence to the hypothesis first put forward by Lane (1937) and then Schumm (1960): alluvial rivers adjust their geometry to the threshold-limiting bed and bank material. It follows that sand-bed rivers may be suspension channels if their banks are composed of more resistant material (Church, 2006), e.g., cohesive sediment and/or vegetation. Gravel rivers, on the other hand, should be less sensitive to bank composition due to the relatively high threshold stress for the entrainment of coarse grains (Schumm, 1960).

\section{Data sources}

The large, global datasets utilized in this paper are identical to those used by Trampush et al. (2014) and Li et al. (2015). They were subsequently combined with a longitudinal profile from the Sacramento River (Singer, 2010), river channel cross sections on the Kosi megafan (Gaurav et al., 2015), and channels formed by seepage erosion in the Apalachicola ravines in Florida (Devauchelle et al., 2011) and in a laboratory (Reitz et al., 2014). This combination of data allows for the following comparisons between localized examples and global trends in river channel characteristics: (1) how changes in the hydraulic geometry and sediment transport regime that a single river experiences across a gravel-sand transition compare to exhibited global trends in hydraulic geometry and Shields stress; and (2) how rivers that orig- 
inate in sandy substrates with little cohesion compare in terms of hydraulic geometry and sediment transport regime to channels with gravel beds. All data used in this analysis (Li et al., 2015; Trampush et al., 2014; Singer, 2010; Gaurav et al., 2015; Devauchelle et al., 2011; Reitz et al., 2014) are available as a Supplement and include bank-full estimates of width, depth, slope, grain size, and discharge.

Our reanalysis requires that we estimate the critical Shields stress for incipient motion, $\tau_{\mathrm{c}}^{*}$, for each data point. Determination of $\tau_{\mathrm{c}}^{*}$ is a notorious problem (Buffington and Montgomery, 1997; Mueller et al., 2005; Lamb et al., 2008; van Rijn, 2016) and, despite the best efforts of researchers, no theory can reliably predict values for the field. Nevertheless, there is strong field and laboratory evidence that $\tau_{\mathrm{c}}^{*}$ varies with site-dependent characteristics, such as slope (Mueller et al., 2005; Lamb et al., 2008; Phillips and Jerolmack, 2014, 2016) and grain size (Shields, 1936; van Rijn, 2016). In this study we use and compare the empirically determined slopedependent relation of Lamb et al. (2008),

$$
\tau_{\mathrm{c}}^{*}=0.15 S^{0.25},
$$

to the Shields-curve fit of van Rijn (2016),

$$
\tau_{* \mathrm{c}}=\frac{0.3}{1+D_{*}}+0.055\left(1-e^{-0.02 D_{*}}\right),
$$

where $D *=(R g)^{1 / 3} D_{50} / v^{2 / 3}$ is dimensionless grain size and $v$ is kinematic viscosity. We note that our findings change little if we use the linear slope-dependent relation of Mueller and Pitlick (2005) instead of Eq. (5).

\section{Hydraulic geometry scaling revisited}

We first examine hydraulic geometry scaling as suggested by the regime Eq. (1). For comparison, we also compute the expectations for a threshold channel following Métivier et al. (2016; Gaurav et al., 2015):

$$
\begin{aligned}
& \frac{W_{\mathrm{bf}}}{D_{50}}=\left[\frac{\pi}{\sqrt{\mu}}\left(\tau_{* \mathrm{c}}\right)^{-1 / 4} \sqrt{\frac{3 C_{f}}{2^{3 / 2} K[1 / 2]}}\right] Q_{*}^{1 / 2} ; \\
& \frac{H_{\mathrm{bf}}}{D_{50}}=\left[\frac{\sqrt{\mu}}{\pi}\left(\tau_{* \mathrm{c}}\right)^{-1 / 4} \sqrt{\frac{3 \sqrt{2} C_{f}}{K[1 / 2]}}\right] Q_{*}^{1 / 2} ; \\
& S=\left[\left(\sqrt{\mu} \tau_{* \mathrm{c}}\right)^{5 / 4} \sqrt{\frac{2^{3 / 2} K[1 / 2]}{3 C_{f}}}\right] Q_{*}^{-1 / 2}
\end{aligned}
$$

For simplicity, we choose values for the following coefficients to be identical to those reported in Métivier et al. (2016): Chézy friction factor $C_{\mathrm{f}} \approx 0.1$, Coulomb friction coefficient $\mu \approx 0.7$, and $K[1 / 2] \approx 1.85$. These values could be manipulated to enhance their fit to data if desired, but this exercise is not performed here. We treat $\tau_{* c}$ in two ways: (1) assuming a constant critical Shields stress with a representative gravel-bed river value $\tau_{* \mathrm{c}}=0.03$ as in Métivier et al. (2016); and (2) using the slope- and grain-size-dependent critical values from Eqs. (5) and (6), respectively.

To first order, gravel- and sand-bedded rivers could be described by a single continuous power-law relation for dimensionless channel width $W_{\mathrm{bf}} / D_{50}$ as a function of $Q_{*}$. A second-order feature is present, however, in the high $Q_{*}$ limit; a subset of sand-bed streams show an upward offset from the general trend (Fig. 2). Dimensionless channel depth $H_{\mathrm{bf}} / D_{50}$ shows similar behavior, except that the high $Q_{*}$ sandy streams show a downward rather than upward offset. In general, gravel-bed rivers are close to threshold predictions, while sand-bed streams depart more significantly, similar to earlier findings by Métivier et al. (2016; Gaurav et al., 2015). Both constant and slope-dependent threshold channel predictions capture the general trends, but predict a systematically steeper scaling exponent than is exhibited by the data. Slope has a behavior that is distinctly different from width and depth; sand-bedded rivers in general display a large offset from the gravel-bedded river trend and a correspondingly large offset from threshold channel predictions (Fig. 2). Slope exhibits more scatter than channel geometry, a common pattern in river data compilations that likely reflects the long timescale associated with slope adjustment (Métivier et al., 2016; Gaurav et al., 2015). Note that, for all variables, the sandy seepage erosion channels in Florida generally plot with the gravel-bedded river data, showing that sand-bedded rivers do not necessarily behave differently from gravel-bedded ones.

One interesting finding is that the product of dimensionless width and depth, i.e., dimensionless channel crosssectional area, shows the tightest relation to $Q_{*}$ and no offset between gravel- and sand-bed channels. This is noteworthy considering that width and depth plots show considerable scatter, so one might expect that their product would exhibit more scatter if the variability was due to random noise or error. This suggests that rivers systematically increase their cross-sectional area $A$ to accommodate increasing discharge regardless of grain size and transport stage; in other words, $A$ is primarily controlled by hydraulics alone (indeed flow resistance, and hence flow velocity $u_{\mathrm{bf}}$, is approximately independent of channel aspect ratio for values $W_{\mathrm{bf}} / H_{\mathrm{bf}}>10$ (Guo and Julien, 2005) that are typical of natural rivers). How changes in $A$ are partitioned into width vs. depth, however, may depend on bed-bank substrate and sediment transport conditions.

\section{Bimodality in the transport states of global datasets}

As the name implies, hydraulic geometry scaling does not consider the transport state of sediment within channels. A simple way to do so is consideration of the bank-full Shields stress $\tau_{* \mathrm{bf}}$. Earlier global compilations of river data sug- 
gested that transport states were bimodal, with gravel-bed rivers clustering around a Shields stress close to the critical value $\left(\tau_{* \mathrm{bf}} \sim 10^{-2}\right)$ and sand-bed rivers clustering around a much higher value $\left(\tau_{* \mathrm{bf}} \sim 10^{0}\right)$ (Paola et al., 1992; Parker et al., 1998; Dade and Friend, 1998). Indeed, we see compelling evidence for this bimodality across a range of slopes and grain sizes in our global compilation (Fig. 3). There are clear deviations from this trend, however; the sandy Florida seepage channels (Devauchelle et al., 2011) and sandy laboratory experimental rivers of Reitz et al. (2014) both plot in the range of phase space otherwise occupied by gravel-bed rivers. What these channels have in common is that they are small, sand-bedded rivers with bank material that is similar in composition to the bed (i.e., sandy).

The case for a continuum of transport states was made more recently by Li et al. (2015), who showed that $\tau_{\text {*bf }}$ is inversely proportional to dimensionless grain size $D_{*}$ and scales with roughly the square root of $S$. They presented a similarity collapse for the data with a best-fit relation $\tau_{* \mathrm{bf}} / S^{0.53}=1220 D_{*}^{-1}$, and a similar result was found by Trampush et al. (2014). Li et al. (2015) concluded that the notion of a constant formative Shields stress for either gravel- or sand-bedded channels was not supported by the data. We reproduce the figure of Li et al. (2015) here, in which the addition of new data (discussed in the previous section) generally supports the similarity collapse (Fig. 4). The sandy Florida seepage channels and experimental rivers, however, fall off this trend.

By assessing transport stage using bank-full Shields stress alone, previous authors either explicitly (Parker et al., 1998, 2007; Wilkerson and Parker, 2010) or implicitly (Li et al., 2015; Trampush et al., 2014) assumed that the critical Shields stress was constant. A recent study by Phillips and Jerolmack (2016), however, showed that when site-specific variations in $\tau_{* \mathrm{c}}$ are taken into account, gravel-bedded rivers exhibit a bank-full Shields stress that is close to the threshold value. We consider transport stage as $\tau_{* b f} / \tau_{* c}$. To test for the influence of variations in $\tau_{* c}$, we examine the distributions of Shields stress and transport stage in which for the latter $\tau_{* \mathrm{c}}$ is estimated from either slope or grain size following Eqs. (5) and (6). The Shields stress distribution is bimodal (Fig. 3). This bimodality becomes slightly more evident in the distributions of transport stage, though there is little difference between the results using the two different estimates for $\tau_{* \mathrm{c}}$ (Fig. 5b, c). The bimodality in Shields stress and transport stage is mirrored by a comparable bimodality in riverbed grain size (Fig. 5d). These findings revive the possibility of a constant transport stage condition that is either close to or far above threshold, but also show that riverbed grain size is insufficient to predict transport stage as threshold sand-bed rivers may readily be found.

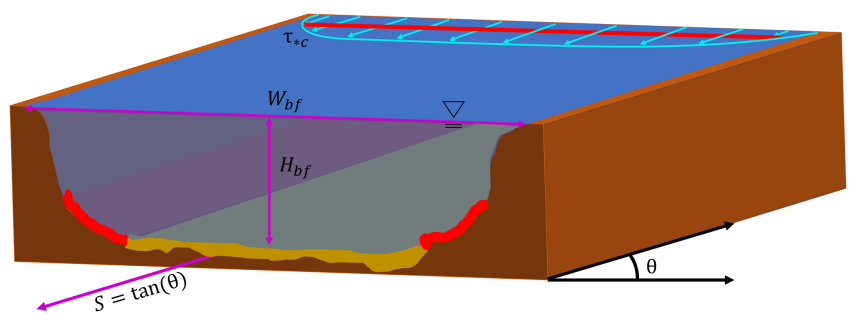

Figure 1. Schematic cross section of a sand-bedded, alluvial river with different bed vs. bank material under bank-full flood conditions. Here $W_{\mathrm{bf}}, H_{\mathrm{bf}}$, and $S$ are bank-full width, bank-full depth, and channel gradient at the cross section, respectively. Cyan lines at the surface illustrate the horizontal stress profile across the channel. Red lines along the channel bottom indicate the toe of the riverbank, i.e., the intersection of bed and bank material. The red line intersecting the cyan velocity profile indicates the threshold stress of the threshold-limiting material, illustrating that the bank toe is at threshold, while Shields stress in the channel center is slightly in excess of threshold.

\section{Bimodality in transport stage along a longitudinal river profile}

The global dataset reveals an apparent dichotomy of transport states that generally (but not always) correspond to sandor gravel-bedded rivers, but the nature of this dichotomy may be partially obscured by confounding variables among disparate river systems that are not accounted for. A useful complementary approach is to examine the longitudinal profile of a single river as it transits from gravel to sand bedded. We utilize data collected by Singer (2010) in his study of the gravel-sand transition of the Sacramento River. We can see that Shields stress is slightly in excess of critical for the gravel-bed portion of the river and far above critical for the sandy portion (Fig. 6). In the gravel-sand transition we observe a flickering between these two distinct states that is indicative of patchiness of the bed materials (Singer, 2010). The fluid shear stress gradually declines downstream (Fig. 6a), and width decreases across the gravel-sand transition but only modestly (Singer, 2010). Bed-sediment size changes abruptly, showing that the large variations in transport stage are overwhelmingly driven by the grain size pattern (Fig. 6b). In summary, the Sacramento River shows the same bimodal behavior as the global dataset in terms of transport stage and grain size. Other factors such as slope or hydraulic geometry do not show this bimodality.

\section{Discussion}

It has long been suggested that bank composition influences the hydraulic geometry of rivers under the premise that effective bank cohesion (silt-clay or vegetation) increases the threshold shear stress, which leads to narrower and deeper channels. The evidence from gravel-bed rivers is that the co- 

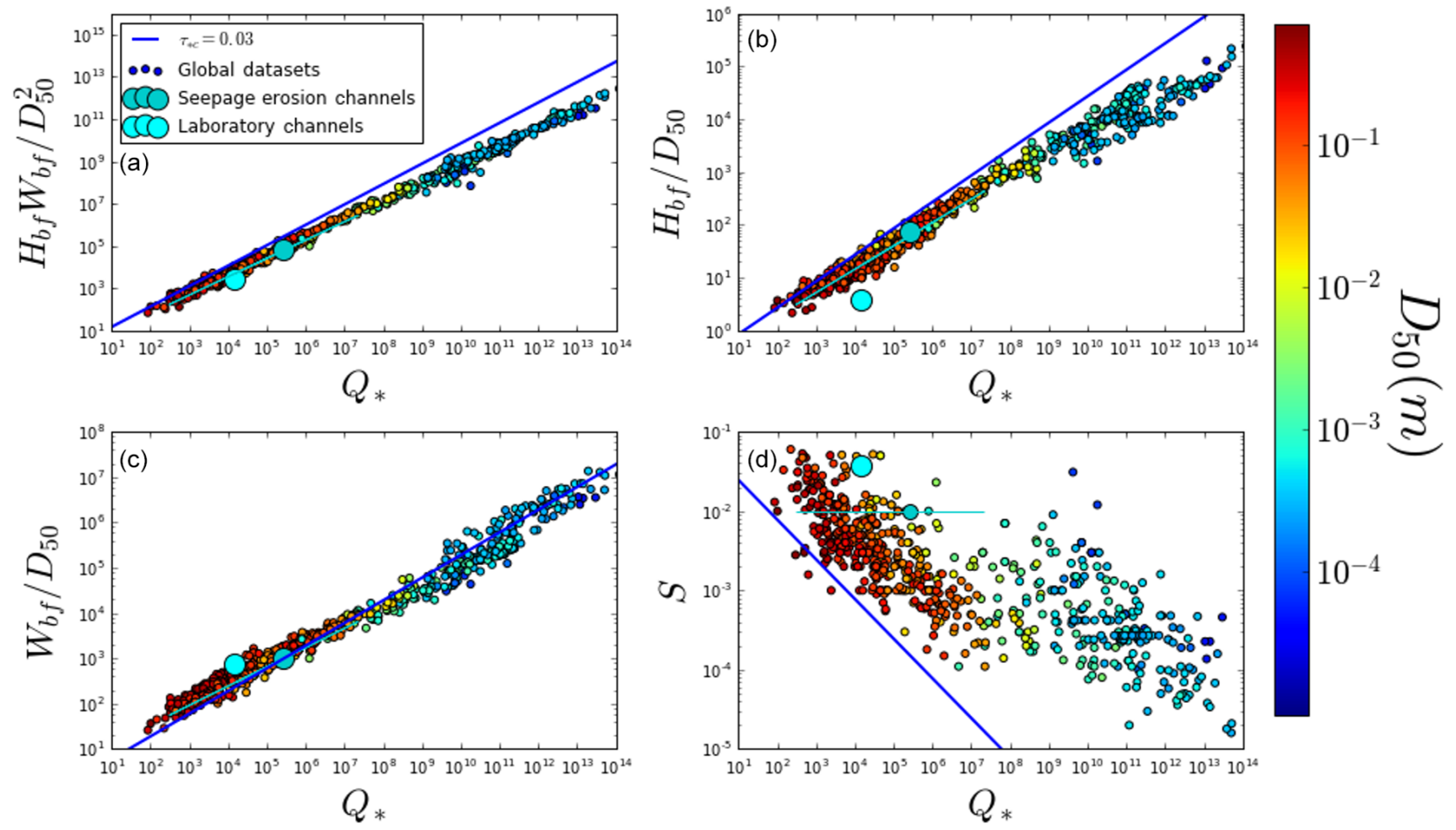

Figure 2. Dimensionless hydraulic geometry scaling for rivers in the global dataset. (a) The cross-sectional area shows a tight relation with discharge across the entire range of data. (b) Depth and (c) width follow similar first-order trends for gravel- vs. sand-bed rivers, but with some offset between these groups. (d) Slope separates sand and gravel rivers. Blue line shows exceptions from the threshold Eq. (7) assuming a constant reference Shields stress for simplicity. We note that the fit does not improve if grain-size- or slope-dependent threshold predictions are used instead. Larger points illustrate the mean of multiple measurements taken along a single longitudinal profile. Cyan error bars represent the range of data and are used because the original study reported only one value for slope and for grain size for all cross sections (Devauchelle et al., 2011).

hesive effect is significant but modest; bank strength changes of up to 2 orders of magnitude correspond to differences in width of 2-3 times (e.g., Andrews, 1984; Millar and Quick, 1993, 1998; Huang and Warner, 1995; Huang and Nanson, 1998). Though there are far fewer studies on sand-bed alluvial rivers, the limited data indicate that the influence of bank cohesion may be larger in these systems (Kleinhans et al., 2015, 2014). The classic study by Fisk (1944) of the Mississippi River showed major narrowing and deepening as the river moved from sandy to clay-rich alluvium, while Schumm (1960) and Schumm (1963) demonstrated that channel aspect ratio $\left(W_{\mathrm{bf}} / H_{\mathrm{bf}}\right)$ was inversely proportional to the percent silt-clay (a proxy for cohesion) in the bed and banks of sand-bed rivers. Interestingly, he found no correlation between aspect ratio and percent silt-clay for gravel-bed rivers (Schumm, 1960). More recent studies on deltaic and tidal channels have also shown that bank strength strongly influences channel geometry (Kleinhans et al., 2009; Edmonds and Slingerland, 2010).

Lane (1937) and Schumm (1960) argued that channels initially cutting into alluvium should widen "until the resis- tance of the banks to scour prevents it" (Schumm, 1960). We rephrase this idea to posit a more specific hypothesis: alluvial rivers, on average, organize their geometry such that the fluid shear stress at the toe of the bank is at the threshold of motion for the bank-full flow (Fig. 1). We consider the bank toe because (1) this is the zone of maximum fluid stress on the bank, and (2) bank-toe erosion is required to undermine upper bank materials. While slumping and block failures may strongly influence the rate of bank erosion with important consequences for river dynamics such as meandering (Parker et al., 2011), these processes likely have little effect on average channel size. For rivers in which the bed and the bank toe are made of the same material, such as laboratory experiments and some natural channels in non-cohesive sediments, we expect to recover the near-threshold "bed-load river" channel predicted by the Parker (1978a) model. For the more common case of rivers having a bank-toe composition that is different from the bed - typically cohesive and/or vegetated banks - we propose that alluvial rivers adjust their geometry to the threshold-limiting material. Thus, in order to maintain a "suspension river" like most natural sand-bed 


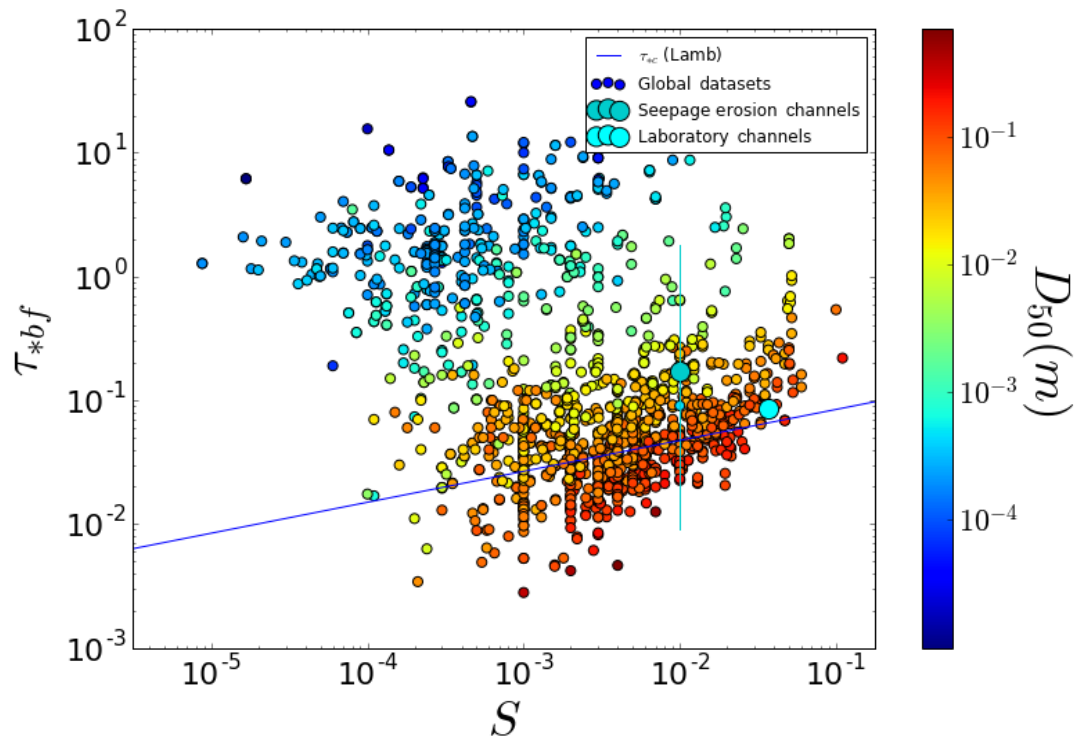

Figure 3. Bank-full Shields stress as a function of stream gradient. Coarse-grained rivers exhibit low Shields stresses with a moderate dependence on slope that roughly follows but is offset from the slope-dependent relation of Lamb et al. (2008) for critical Shields stress (solid line). Fine-grained rivers cluster well in excess of the threshold of motion. River channels originating in sandy substrates found in natural (Devauchelle et al., 2011) or laboratory (Reitz et al., 2014) environments are shown to be in the Shields stress space typically populated by gravel-bedded rivers.

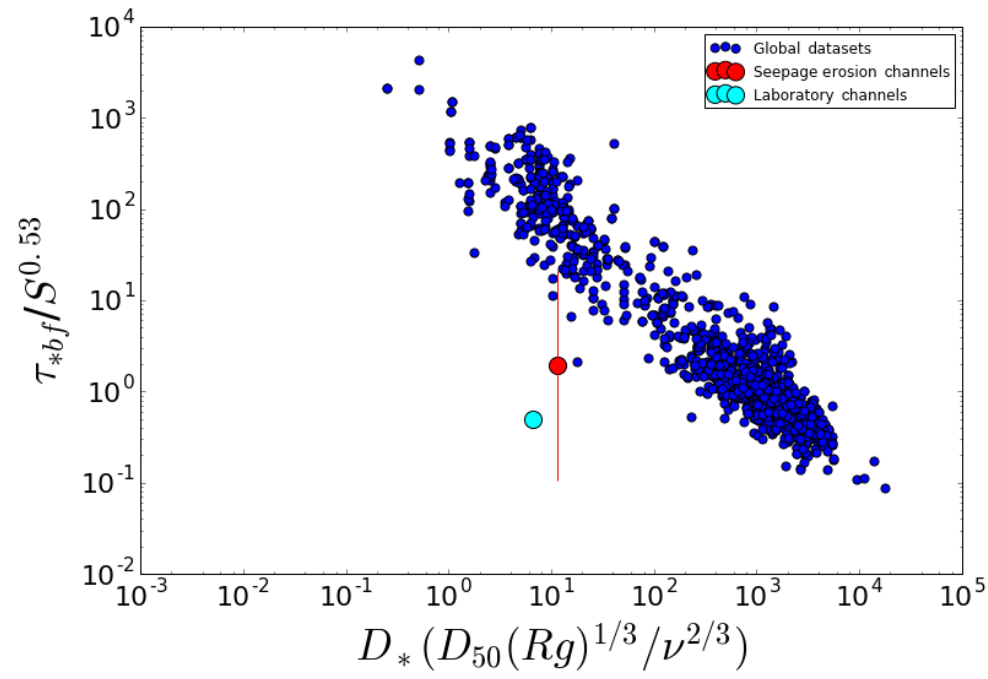

Figure 4. A recreation of the diagram from Li et al. (2015) that makes the case for a continuum of sediment transport regimes. Additional data have been added to the diagram from an additional global dataset (Trampush et al., 2014) and various longitudinal profiles (Singer, 2010; Gaurav et al., 2015; Devauchelle et al., 2011). Clear deviations from the trend are demonstrated by river channels formed by seepage erosion in sand (with mean and error bars the same as in Fig. 3) and channels formed in sand in laboratory experiments (Reitz et al., 2014) that are represented by the larger red and cyan points, respectively.

channels, the banks must be composed of cohesive sediment with a significantly higher entrainment threshold than the bed material. Indeed, Church (2006) noted that sand-bed channels often have silt-clay banks that experience little to no deformation, while channel-bed sands are completely suspended.
Unfortunately, reported measurements of hydraulic channel geometry rarely include information about bank materials. To test the threshold-limiting idea indirectly, we consider the relative mobility of bed and bank materials as a function of grain size. We do not consider vegetation explicitly; however, we note that numerous studies have analyzed the effects 

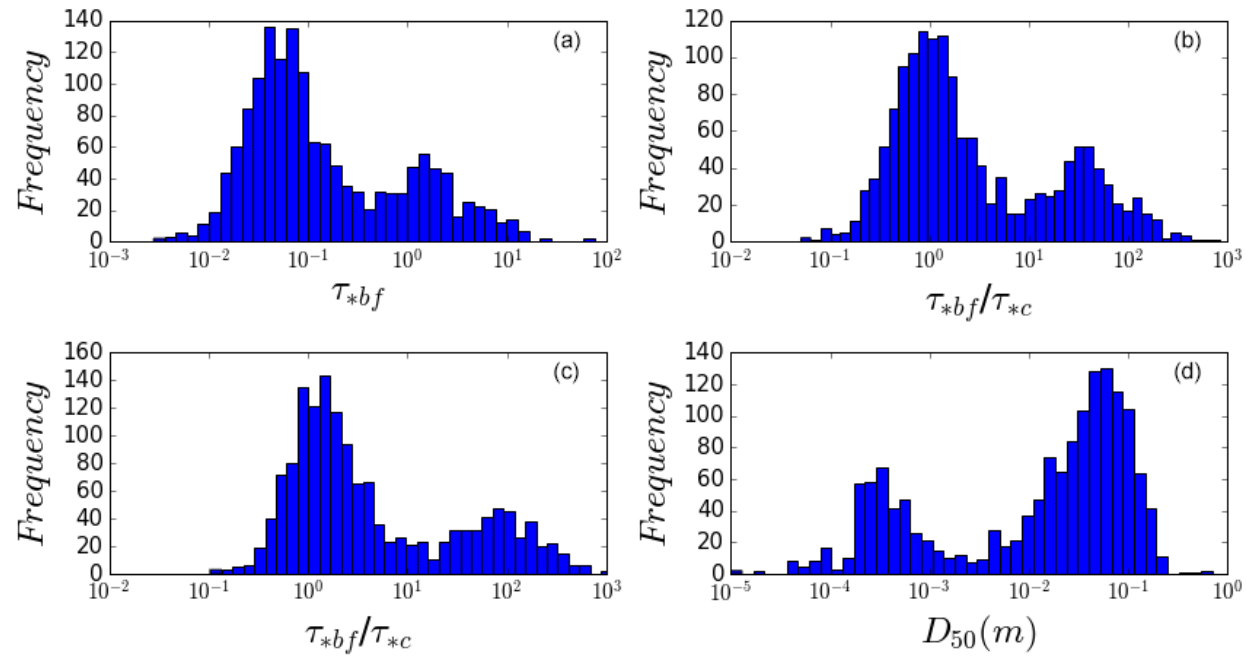

Figure 5. Distributions of (a) shields stress, (b) transport stage estimated using grain size (van Rijn, 2016), (c) transport stage estimated using slope (Lamb et al., 2008), and (d) median riverbed grain size. All distributions are bimodal, with near-threshold gravel rivers and far-above-threshold sandy rivers.
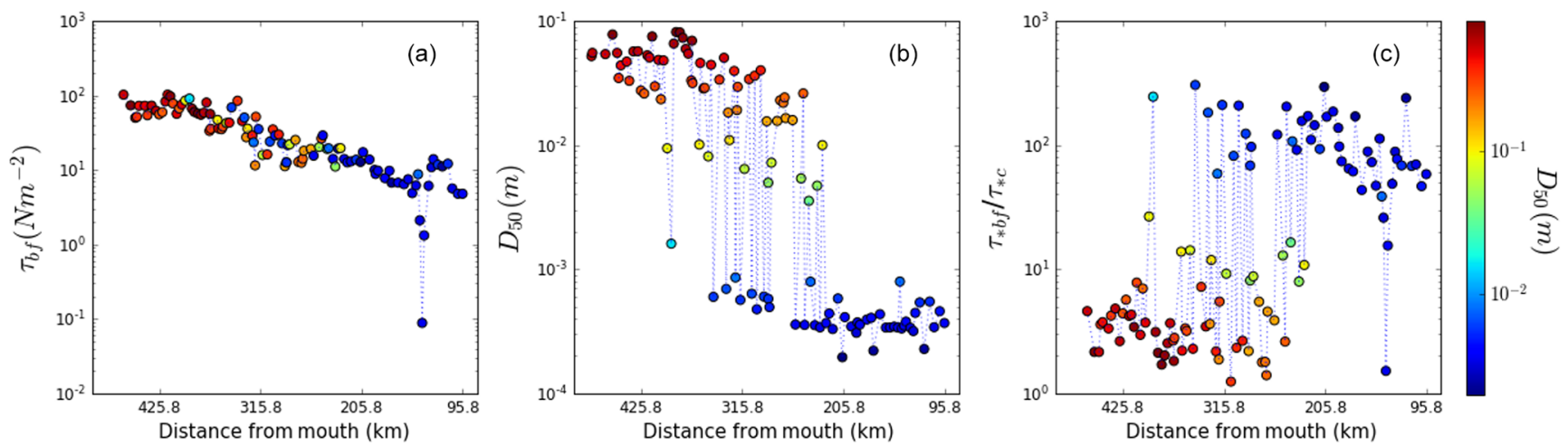

Figure 6. Longitudinal profile data from the Sacramento River up to approximately $500 \mathrm{~km}$ upstream of the river mouth (Singer, 2010). (a) Fluid shear stress decreases gradually and continuously across the gravel-sand transition. (b) Grain size behavior downstream is bimodal, changing rapidly from gravel to sand. (c) Shields stress shows abrupt transition from near threshold to far above threshold across the gravelsand transition.

of vegetation on erosion thresholds (Micheli and Kirchner, 2002; Abernethy and Rutherfurd, 2001). It is important to point out that Shields stress is not the relevant parameter for cohesive materials, and particle weight does not adequately describe resistance to motion. Dimensional fluid threshold stress is usually reported in studies involving cohesive sediment. Considering non-cohesive materials and neglecting slope effects, the threshold fluid stress determined from the Shields curve increases monotonically with increasing grain size following the relation presented in Eq. (6).

Cohesion becomes significant for particles that are siltsized and smaller due to surface charge effects, which increases the threshold for entrainment compared to predictions from the Shields curve (Kemper et al., 1987; Kothyari and Jain, 2008). As a result, sand is the most easily entrained material: larger particles are harder to move due to their mass, while smaller particles are harder to move due to cohesion. Of course, most stream banks are composed of mixtures of cohesive and non-cohesive sediments. The threshold entrainment stress for sand increases rapidly with an increasing fraction of clay and silt, with reported increases of up to 2 orders of magnitude for clay-rich riverbanks (Kothyari and Jain, 2008). For gravel particles of order centimeter and larger, however, the entrainment stress varies little with the addition of clay and silt (Kothyari and Jain, 2008). Taken together, we naively expect that rivers with bed sediment $D_{50}>10^{-2} \mathrm{~m}$ should organize to a threshold shear stress that is slightly in excess of the threshold predicted by the Shields curve. For natural rivers with bed sediment smaller than about a centimeter, cohesive sediments (if present) will lead to channel banks with entrainment thresholds that are larger than predicted by the Shields curve. The minimum 


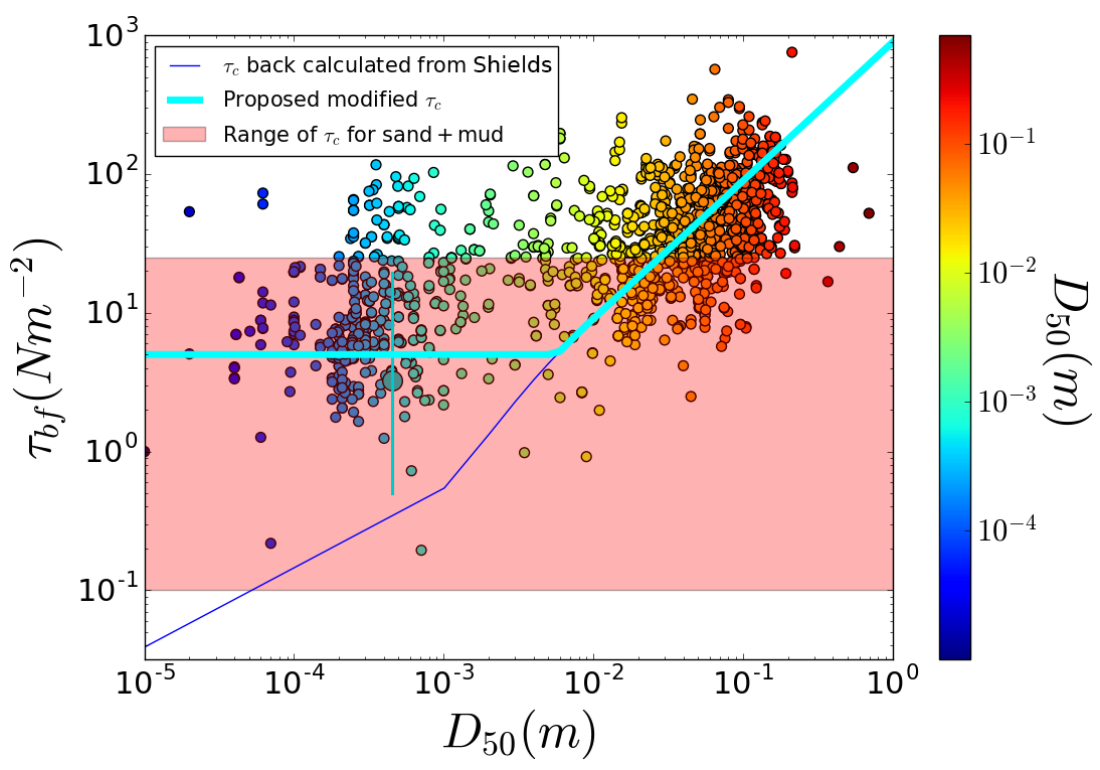

Figure 7. Potential adjustment of riverbed shear stress to the threshold-limiting material for the global data. The rising line from left to right indicates expected critical shear stress determined from grain size based on the Shields curve fit of van Rijn (2016). Gravel-bed rivers generally fall along this line, but sandy rivers generally plot significantly above it. Flat line shows a reference critical shear stress for the middle of the range of sand-mud mixtures. Cyan line indicates the trace of the threshold-limiting stress. For rivers with bed-sediment grain sizes smaller than about a millimeter, we expect bank material to be threshold limiting; for gravel-bed rivers, the bed is expected to be threshold limiting.

threshold fluid stress for a sand-bed river is $\tau_{\mathrm{b}} \sim 0.1 \mathrm{~N} \mathrm{~m}^{-2}$ based on the Shields curve. Without knowledge of bank materials in the data used here, we use results from a systematic study that examined the influence of silt-clay content on the erosion threshold of natural sandy riverbanks. Julian and Torres (2006) reported a maximum stress of $\tau_{\mathrm{b}} \approx 25 \mathrm{~N} \mathrm{~m}^{-2}$ for banks composed entirely of silt and clay. For typical banks with silt-clay fractions of a few tens of percent and/or moderate vegetation coverage, a typical value for the critical stress is $\tau_{\mathrm{b}} \approx 5 \mathrm{~N} \mathrm{~m}^{-2}$ (Julian and Torres, 2006; Tal and Paola, 2007; Braudrick et al., 2009).

Turning to the global dataset, we compare the bank-full shear stress $\tau_{\mathrm{bf}}$ to bed-sediment grain size $D_{50}$ for all rivers (Fig. 7). While there is significant scatter, we notice a general pattern in the data: sand-bed rivers show no relation between bank-full shear stress and bed-sediment grain size, while gravel-bed rivers exhibit increasing shear stress with grain size. Projecting the threshold stress based on the Shields curve onto the data, we see that gravel-bed rivers generally follow the curve, while sandy rivers plot significantly above it. The range of $\tau_{\mathrm{bf}}$ for sandy rivers overlaps and is slightly offset from the range of threshold stresses reported for sand-mud mixtures (Fig. 7). The "typical value" of $\tau_{\mathrm{b}}=5 \mathrm{~N} \mathrm{~m}^{-2}$ runs through the middle of sandy rivers. The threshold-limiting material may be assessed by comparing the threshold stress of mud-sand mixtures to the threshold stress determined from the Shields curve; we see that most rivers with $D_{50}>1 \mathrm{~cm}$ are limited by gravel mobility, while most rivers with $D_{50}<1 \mathrm{~mm}$ are limited by bank mobility (if cohesive sediment is present).

The above trends provide tentative, albeit equivocal, support for the hypothesis that all alluvial rivers are nearthreshold channels adjusted to the threshold-limiting material. For the case of gravel-bed rivers, this corresponds to a transport stage close to 1 for the bed material at bank-full. For sand-bed rivers with cohesive banks, we expect the transport stage of bed material to be roughly the ratio of the bank to bed entrainment thresholds, which could be in the range $10^{0} \leq \tau_{* \mathrm{bf}} / \tau_{* \mathrm{c}}<10^{3}$. Because sand has the lowest threshold and most natural riverbanks contain some cohesive materials, the transport stage for sandy rivers is typically much greater than 1 , leading to suspension channels. Given the paucity of alluvial riverbeds with median grain sizes between 1 and $10 \mathrm{~mm}$ - the range in which we expect cohesive banks to become important - these factors give rise to a bimodal distribution of transport stage. In terms of hydraulic geometry, data indicate that cross-sectional area is controlled primarily by hydraulic conveyance as it has a very tight relation with bank-full discharge for all rivers. The partitioning of this area into width and depth appears to be related to the threshold constraint imposed by bank-toe material.

We close this section with a brief but important aside on the distinction between hydraulic geometry and dynamics. The idea that all alluvial rivers are near threshold may at first seem incompatible with the intrinsic and incessant dynamics we observe: widening-narrowing, meandering, sorting, and 
bed-bar form evolution. In this context the (near-)threshold channel geometry is the statistically expected behavior in a dynamic, stochastic system - analogous to a mean bed-load flux or Reynolds averaging in fluid mechanics - that does not represent system behavior at any particular instant (Furbish et al., 2016). The experimental findings of Reitz et al. (2014) make this point well: "Although individual channels in the braided river are constantly changing shape through scour and fill, these appear to be fluctuations around a robust (near-threshold) geometry that becomes apparent when many individual channel geometries are averaged together." Some of the scatter in hydraulic geometry scaling plots may be due to a variety of factors, such as influences from vegetation, localized and/or temporary imbalances between the rate of floodplain formation and bank failure, and partial submergence of grains in the flow.

\section{Conclusions}

We propose that all alluvial rivers, regardless of their bedmaterial grain size, organize their hydraulic geometry such that they cluster around the threshold of motion for the most resistant material - the structural component of the channel that is most difficult to mobilize. For coarse-grained rivers, the threshold-limiting material is the gravel that comprises the bed and bank toe. In contrast, the threshold-limiting material in sand-bedded rivers is not the bed material, but the cohesive mixture of mud and sand (and vegetation) that makes up the toe of the riverbank. Thus, we posit that it is the difference in entrainment threshold between the non-cohesive bed and cohesive banks that facilitates suspended-sediment transport in sandy rivers. We expect that in very fine-grained mud channels, the threshold-limiting material is the mud that makes up both the bed and the bank toe. Consideration of the slope or grain size dependence of the critical Shields stress shows that alluvial rivers are bimodal in terms of transport stage and bed-material grain size and that these modes correspond generally (but not always) to bed-load gravel rivers and suspension sand rivers. We acknowledge, however, that other factors unaccounted for in our simple analysis must also play a role. For example, form drag due to roughness on multiple scales (grains, bed forms, bars, meanders) can drastically change the effective bed stress (Kean and Smith, 2006). We suspect that properly accounting for flow resistance would reveal a stronger signal of near-threshold organization. Of course, determination of the entrainment threshold at the bank toe is needed to provide direct confirmation of the hypothesis we propose here. Experiments have qualitatively demonstrated the influence of cohesion on channel geometry (Kothyari and Jain, 2008; Tal and Paola, 2007; Braudrick et al., 2009), but a systematic examination of channel shape as a function of increasing cohesion in sand-mud mixtures is necessary to demonstrate the viability of the thresholdlimiting hypothesis.
Data availability. All data used in this analysis (Li et al., 2015; Trampush et al., 2014; Singer, 2010; Gaurav et al., 2015; Devauchelle et al., 2011; Reitz et al., 2014) are available as a Supplement and include bank-full estimates of width, depth, slope, grain size, and discharge.

Supplement. The supplement related to this article is available online at: https://doi.org/10.5194/esurf-6-583-2018-supplement.

Author contributions. KBJD performed the research and analyzed the data, DJJ supervised the research, and both authors wrote the paper.

Competing interests. The authors declare that they have no conflict of interest.

Disclaimer. The views and conclusions contained in this document are those of the authors and should not be interpreted as representing the official policies, either expressed or implied, of the Army Research Laboratory or the U.S. Government.

Acknowledgements. We thank Michael Singer and Olivier Devauchelle for sharing their data for the Sacramento River and seepage erosion channels in Florida, respectively, and James Pizzuto for useful comments that helped to frame aspects of this paper. The research was sponsored by the Army Research Laboratory and was accomplished under grant number W911-NF-16-1-0290.

Edited by: Tom Coulthard

Reviewed by: Maarten Kleinhans, Andrew Wickert, Shawn Chartrand, and one anonymous referee

\section{References}

Abernethy, B. and Rutherfurd, I. D.: The distribution and strength of riparian tree roots in relation to riverbank reinforcement, Hydrol. Process., 15, 63-79, 2001.

Andrews, E. D.: Bed-material entrainment and hydraulic geometry of gravel-bed rivers in Colorado, Geol. Soc. Am. Bull., 95, $371-$ 378, 1984.

Blom, A., Chavarrías, V., Ferguson, R. I., and Viparelli, E.: Advance, Retreat, and Halt of Abrupt Gravel-Sand Transitions in Alluvial Rivers, Geophys. Res. Lett., 44, 9751-9760, 2017.

Braudrick, C. A., Dietrich, W. E., Leverich, G. T., and Sklar, L. S.: Experimental evidence for the conditions necessary to sustain meandering in coarse-bedded rivers, P. Natl. Acad. Sci. USA, 106, 16936-16941, 2009.

Buffington, J. M. and Montgomery, D. R.: A systematic analysis of eight decades of incipient motion studies, with special reference to gravel-bedded rivers, Water Resour. Res., 33, 1993-2029, 1997.

Church, M.: Bed material transport and the morphology of alluvial river channels, Annu. Rev. Earth Pl. Sc., 34, 325-354, 2006. 
Dade, W. B. and Friend, P. F.: Grain-size, sediment-transport regime, and channel slope in alluvial rivers, J. Geol., 106, 661676, 1998

Devauchelle, O., Petroff, A. P., Lobkovsky, A., and Rothman, D. H.: Longitudinal profile of channels cut by springs, J. Fluid Mech., 667, 38-47, 2011.

Eaton, B. C. and Church, M.: Predicting downstream hydraulic geometry: a test of rational regime theory, J. Geophys. Res.-Earth, 112, F3025, https://doi.org/10.1029/2006JF000734, 2007.

Eaton, B. C., Church, M., and Millar, R. G.: Rational regime model of alluvial channel morphology and response, Earth Surf. Proc. Land., 29, 511-529, 2004.

Edmonds, D. A. and Slingerland, R. L.: Significant effect of sediment cohesion on delta morphology, Nat. Geosci., 3, 105-109, 2010.

Federici, B. and Paola, C.: Dynamics of channel bifurcations in noncohesive sediments, Water Resour. Res., 39, 1162, https://doi.org/10.1029/2002WR001434, 2003.

Ferguson, R.: Hydraulic and sedimentary controls of channel pattern, River channels: Environments and processes, Basil Blackwell, Oxford, UK, 129-158, 1987.

Fisk, H. N.: Geological investigation of the alluvial valley of the lower Mississippi valley, United States, War Department, Corps of Engineers, Office, President, Mississippi River commission, Vicksburg, Mississippi, USA, 1944.

Furbish, D. J., Schmeeckle, M. W., Schumer, R., and Fathel, S. L.: Probability distributions of bed load particle velocities, accelerations, hop distances, and travel times informed by Jaynes's principle of maximum entropy, J. Geophys. Res.-Earth, 121, 13731390, 2016.

Gaurav, K., Métivier, F., Devauchelle, O., Sinha, R., Chauvet, H., Houssais, M., and Bouquerel, H.: Morphology of the Kosi megafan channels, Earth Surf. Dynam., 3, 321-331, https://doi.org/10.5194/esurf-3-321-2015, 2015.

Glover, R. E. and Florey, Q.: Stable channel profiles, United States, Department of the Interior, Bureau of Reclamation, Design and Construction Division, Engineering Laboratories Branch, Denver, Colorado, USA, 1951.

Guo, J. and Julien, P. Y.: Shear stress in smooth rectangular openchannel flows, J. Hydraul. Eng., 131, 30-37, 2005.

Henderson, F. M.: Stability of alluvial channels, J. Hydr. Eng. Div.ASCE, 87, 109-138, 1961.

Huang, H. Q. and Nanson, G. C.: The influence of bank strength on channel geometry: an integrated analysis of some observations, Earth Surf. Proc. Land., 23, 865-876, 1998.

Huang, H. Q. and Warner, R. F.: The multivariate controls of hydraulic geometry: a causal investigation in terms of boundary shear distribution, Earth Surf. Proc. Land., 20, 115-130, 1995.

Ikeda, S. and Nishimura, T.: Bed topography in bends of sand-silt rivers, J. Hydraul. Eng., 111, 1397-1410, 1985.

Ikeda, S., Parker, G., and Kimura, Y.: Stable width and depth of straight gravel rivers with heterogeneous bed materials, Water Resour. Res., 24, 713-722, 1988.

Julian, J. P. and Torres, R.: Hydraulic erosion of cohesive riverbanks, Geomorphology, 76, 193-206, 2006.

Kean, J. W. and Smith, J. D.: Form drag in rivers due to small-scale natural topographic features: 1. Regular sequences, J. Geophys. Res.-Earth, 111, F04009, https://doi.org/10.1029/2006JF000467, 2006.
Kemper, W., Rosenau, R., and Dexter, A.: Cohesion development in disrupted soils as affected by clay and organic matter content and temperature, Soil Sci. Soc. Am. J., 51, 860-867, 1987.

Kleinhans, M. G., Schuurman, F., Bakx, W., and Markies, H.: Meandering channel dynamics in highly cohesive sediment on an intertidal mud flat in the Westerschelde estuary, the Netherlands, Geomorphology, 105, 261-276, 2009.

Kleinhans, M. G., van Dijk, W. M., van de Lageweg, W. I., Hoyal, D. C., Markies, H., van Maarseveen, M., Roosendaal, C., van Weesep, W., van Breemen, D., Hoendervoogt, R., and Cheshier, N.: Quantifiable effectiveness of experimental scaling of riverand delta morphodynamics and stratigraphy, Earth-Sci. Rev., 133, 43-61, 2014

Kleinhans, M. G., Braudrick, C., Van Dijk, W. M., Van de Lageweg, W. I., Teske, R., and Van Oorschot, M.: Swiftness of biomorphodynamics in Lilliput-to Giant-sized rivers and deltas, Geomorphology, 244, 56-73, 2015.

Kothyari, U. C. and Jain, R. K.: Influence of cohesion on the incipient motion condition of sediment mixtures, Water Resour. Res. 44, W04410, https://doi.org/10.1029/2007WR006326, 2008.

Lacey, G.: Stable channels in alluvium, Minutes of the Proceedings of the Institution of Civil Engineeers, Thomas Telford-ICE Virtual Library, 259-292, https://doi.org/10.1680/imotp.1930.15592, 1930.

Lamb, M. P. and Venditti, J. G.: The grain size gap and abrupt gravel-sand transitions in rivers due to suspension fallout, Geophys. Res. Lett., 43, 3777-3785, 2016.

Lamb, M. P., Dietrich, W. E., and Venditti, J. G.: Is the critical Shields stress for incipient sediment motion dependent on channel-bed slope?, J. Geophys. Res.-Earth, 113, F02008, https://doi.org/10.1029/2007JF000831, 2008.

Lane, E. W.: Stable Channels in Erodible Material, American Society of Civil Engineers, available at: https://books.google.com/ books?id=8rnOtgAACAAJ (last access: 16 March 2017), 1935.

Leopold, L. B. and Maddock, T.: The hydraulic geometry of stream channels and some physiographic implications, vol. 252, US Government Printing Office, Washington, D.C., USA, 1953.

Li, C., Czapiga, M. J., Eke, E. C., Viparelli, E., and Parker, G.: Variable Shields number model for river bankfull geometry: bankfull shear velocity is viscosity-dependent but grain size-independent, J. Hydraul. Res., 53, 36-48, 2015.

Marra, W. A., McLelland, S. J., Parsons, D. R., Murphy, B. J., Hauber, E., and Kleinhans, M. G.: Groundwater seepage landscapes from distant and local sources in experiments and on Mars, Earth Surf. Dynam., 3, 389-408, https://doi.org/10.5194/esurf-3-389-2015, 2015.

Métivier, F., Devauchelle, O., Chauvet, H., Lajeunesse, E., Meunier, P., Blanckaert, K., Ashmore, P., Zhang, Z., Fan, Y., Liu, Y., Dong, Z., and Ye, B.: Geometry of meandering and braided gravel-bed threads from the Bayanbulak Grassland, Tianshan, P. R. China, Earth Surf. Dynam., 4, 273-283, https://doi.org/10.5194/esurf-4273-2016, 2016.

Métivier, F., Lajeunesse, E., and Devauchelle, O.: Laboratory rivers: Lacey's law, threshold theory, and channel stability, Earth Surf. Dynam., 5, 187-198, https://doi.org/10.5194/esurf-5-187-2017, 2017.

Micheli, E. and Kirchner, J.: Effects of wet meadow riparian vegetation on streambank erosion. 2. Measurements of vegetated bank 
strength and consequences for failure mechanics, Earth Surf. Proc. Land., 27, 687-697, 2002.

Millar, R. G. and Quick, M. C.: Effect of bank stability on geometry of gravel rivers, J. Hydraul. Eng., 119, 1343-1363, 1993.

Millar, R. G. and Quick, M. C.: Stable width and depth of gravel-bed rivers with cohesive banks, J. Hydraul. Eng., 124, 1005-1013, 1998.

Miller, K. L., Szabó, T., Jerolmack, D. J., and Domokos, G.: Quantifying the significance of abrasion and selective transport for downstream fluvial grain size evolution, J. Geophys. Res.-Earth, 119, 2412-2429, 2014.

Mueller, E. R. and Pitlick, J.: Morphologically based model of bed load transport capacity in a headwater stream, J. Geophys. Res.-Earth, 110, F02016, https://doi.org/10.1029/2003JF000117, 2005.

Mueller, E. R., Pitlick, J., and Nelson, J. M.: Variation in the reference Shields stress for bed load transport in gravelbed streams and rivers, Water Resour. Res., 41, W04006, https://doi.org/10.1029/2004WR003692, 2005.

Nanson, G. and Young, R.: Downstream reduction of rural channel size with contrasting urban effects in small coastal streams of southeastern Australia, J. Hydrol., 52, 239-255, 1981.

Paola, C., Heller, P. L., and Angevine, C. L.: The large-scale dynamics of grain-size variation in alluvial basins, 1: Theory, Basin Res., 4, 73-90, 1992.

Parker, G.: Self-formed straight rivers with equilibrium banks and mobile bed. Part 2. The gravel river, J. Fluid Mech., 89, 127-146, 1978a.

Parker, G.: Self-formed straight rivers with equilibrium banks and mobile bed. Part 1. The sand-silt river, J. Fluid Mech., 89, 109$125,1978 b$.

Parker, G., Paola, C., Whipple, K. X., and Mohrig, D.: Alluvial fans formed by channelized fluvial and sheet flow. I: Theory, J. Hydraul. Eng., 124, 985-995, 1998.

Parker, G., Wilcock, P. R., Paola, C., Dietrich, W. E., and Pitlick, J.: Physical basis for quasi-universal relations describing bankfull hydraulic geometry of single-thread gravel bed rivers, J. Geophys. Res.-Earth, 112, F04005, https://doi.org/10.1029/2006JF000549, 2007.

Parker, G., Shimizu, Y., Wilkerson, G., Eke, E. C., Abad, J. D., Lauer, J., Paola, C., Dietrich, W. E., and Voller, V.: A new framework for modeling the migration of meandering rivers, Earth Surf. Proc. Land., 36, 70-86, 2011.

Pfeiffer, A. M., Finnegan, N. J., and Willenbring, J. K.: Sediment supply controls equilibrium channel geometry in gravel rivers, $\mathrm{P}$. Natl. Acad. Sci. USA, 114, 3346-3351, 2017.

Phillips, C. B. and Jerolmack, D. J.: Dynamics and mechanics of bed-load tracer particles, Earth Surf. Dynam., 2, 513-530, https://doi.org/10.5194/esurf-2-513-2014, 2014.

Phillips, C. B. and Jerolmack, D. J.: Self-organization of river channels as a critical filter on climate signals, Science, 352, 694-697, 2016.
Pitlick, J., Marr, J., and Pizzuto, J.: Width adjustment in experimental gravel-bed channels in response to overbank flows, J. Geophys. Res.-Earth, 118, 553-570, 2013.

Reitz, M. D., Jerolmack, D. J., Lajeunesse, E., Limare, A., Devauchelle, O., and Métivier, F.: Diffusive evolution of experimental braided rivers, Phys. Rev. E, 89, 052809, https://doi.org/10.1103/PhysRevE.89.052809, 2014.

Richards, K.: Fluvial geomorphology, Prog. Phys. Geog., 11, 432 457, 1987.

Schumm, S.: The shape of alluvial channels in relation to sediment type, USGS Prof. Pap, U.S. Government Printing Office, Washington, D.C., USA, 1960.

Schumm, S. A.: Sinuosity of alluvial rivers on the Great Plains, Geol. Soc. Am. Bull., 74, 1089-1100, 1963.

Schwendel, A. C., Nicholas, A. P., Aalto, R. E., Sambrook Smith, G. H., and Buckley, S.: Interaction between meander dynamics and floodplain heterogeneity in a large tropical sand-bed river: the Rio Beni, Bolivian Amazon, Earth Surf. Proc. Land., 40, 2026-2040, 2015.

Shields, A.: Application of similarity principles and turbulence research to bed-load movement, CalTech library, Soil Conservation Service Cooperative Laboratory, California Institute of Technology, Pasadena, California, USA, 1936.

Singer, M. B.: Downstream patterns of bed material grain size in a large, lowland alluvial river subject to low sediment supply, Water Resour. Res., 44, W12202, https://doi.org/10.1029/2008WR007183, 2008.

Singer, M. B.: Transient response in longitudinal grain size to reduced gravel supply in a large river, Geophys. Res. Lett., 37, L18403, https://doi.org/10.1029/2010GL044381, 2010.

Tal, M. and Paola, C.: Dynamic single-thread channels maintained by the interaction of flow and vegetation, Geology, 35, 347-350, 2007.

Trampush, S., Huzurbazar, S., and McElroy, B.: Empirical assessment of theory for bankfull characteristics of alluvial channels, Water Resour. Res., 50, 9211-9220, 2014.

van Rijn, L. C.: Initiation of Motion and Suspension; Critical BedShear Stress for Sand-Mud Mixtures, available at: https://www. leovanrijn-sediment.com/ (last access: 16 March 2017), 2016.

Venditti, J., Humphries, R., Allison, M., Nittrouer, J., and Church, M.: Morphology and dynamics of a gravel-sand transition, in: Proceedings of the 9th Federal Interagency Sedimentation Conference, 27 June-1 July 2010, Las Vegas, NV, USA, vol. 11, 2010.

Venditti, J. G., Domarad, N., Church, M., and Rennie, C. D.: The gravel-sand transition: Sediment dynamics in a diffuse extension, J. Geophys. Res.-Earth, 120, 943-963, 2015.

Wilkerson, G. V. and Parker, G.: Physical basis for quasi-universal relationships describing bankfull hydraulic geometry of sand-bed rivers, J. Hydraul. Eng., 137, 739-753, 2010. 